\title{
Periostin deposition in the stroma of invasive and intraductal neoplasms of the pancreas
}

\author{
Noriyoshi Fukushima ${ }^{1}$, Yoshinao Kikuchi ${ }^{1}$, Takashi Nishiyama ${ }^{1,2}$, Akira Kudo ${ }^{2}$ and \\ Masashi Fukayama ${ }^{1}$ \\ ${ }^{1}$ Department of Pathology, Graduate School of Medicine, The University of Tokyo, Tokyo, Japan and \\ ${ }^{2}$ Department of Biological Information, Tokyo Institute of Technology, Yokohama, Japan
}

\begin{abstract}
Desmoplasia is a common feature of infiltrating ductal adenocarcinoma of the pancreas. This process is intricately interacted between the host and neoplastic cells. Recently, by transcriptome analysis, periostin was identified as a significantly highly expressed gene in pancreatic stellate cells. To investigate the characteristics of periostin immunodeposition in pancreatic ductal neoplasms, we performed immunohistochemistry and in situ hybridization, focusing on tumor-stromal cells interactions. Eighty-one surgically resected pancreatic lesions, including 35 pancreatic ductal adenocarcinoma, 26 intraductal papillary-mucinous neoplasms, 11 mucinous cystic neoplasms and 9 chronic pancreatitis, were studied. In all ductal adenocarcinomas, periostin deposition was observed in the stroma around the infiltrating cancer on immunohistochemistry. Cellular stroma of mucinous cystic neoplasm, called 'ovarian-type' stroma, did not show periostin deposition. In chronic pancreatitis, most of the staining patterns of periostin were perilobular and meshwork-like. Periostin gene expression was detected solely in the stromal cells on in situ hybridization. Intraductal papillary-mucinous neoplasms were classified into four groups on the basis of the histological grade, namely, adenoma, noninvasive adenocarcinoma, adenocarcinoma with microscopical invasion and with macroscopically evident invasion. In intraductal papillary-mucinous neoplasm, periostin deposition in the periductal stroma increased in frequency and intensity in adenocarcinoma compared with adenomas $(P=0.014)$. Furthermore, our results showed that a higher frequency of periostin deposition was correlated with a higher frequency of 'intestinal phenotype' of proliferating epithelium $(P=0.036)$ and laminin-5 $\gamma 2$ chain expression $(P<0.001)$ in intraductal papillary-mucinous neoplasm, the latter of which is frequently expressed in invasive carcinoma. This is the first report to describe the periostin immunohistochemistry in intraductal papillary mucinous neoplasm of the pancreas.
\end{abstract}

Modern Pathology (2008) 21, 1044-1053; doi:10.1038/modpathol.2008.77; published online 16 May 2008

Keywords: intraductal papillary-mucinous neoplasm; pancreas; periostin; invasion; immunohistochemistry

Pancreatic ductal adenocarcinoma is often associated with a prominent host desmoplastic response. This host response at the site of primary invasion has been considered an important factor in pancreatic cancer progression. Indeed, evidence exists for interactions between pancreatic cancer cells and stromal fibroblasts that affect the invasive phenotype of pancreatic cancer. ${ }^{1,2}$ Many of the genes identified were expressed specifically by stromal cells adjacent to the neoplastic epithelium. ${ }^{1,3}$

Periostin is a secreted $90 \mathrm{kDa}$ protein originally identified as an osteoblast-specific factor preferentially

Correspondence: Dr N Fukushima, MD, PhD, Department of Pathology, The University of Tokyo, Hongo 7-3-1, Bunkyo-ku, Tokyo 113-0033, Japan.

E-mail: nfukushima-tky@umin.ac.jp

Received 04 November 2007; revised 16 April 2008; accepted 17 April 2008; published online 16 May 2008 expressed in the periosteum in bone tissues.,5 Recently, periostin gene was identified as a differentially expressed gene in various types of cancer including the head and neck, ${ }^{6}$ lung, ${ }^{7}$ ovary, ${ }^{8}$ breast,,${ }^{9,10}$ colon ${ }^{11}$ and pancreatic cancer. ${ }^{12,13}$ The periostin gene was also identified by transcriptome analysis in pancreatic stellate cells. ${ }^{14}$ This result was reasonable because periostin expression in pancreatic cancer increased more than 35-fold compared with normal pancreas tissue, but increased less than 3-fold compared with chronic pancreatitis in the previous microarray study. ${ }^{12}$ Erkan et $a l^{15}$ and Baril et al ${ }^{16}$ showed strong stromal staining of periostin in pancreatic cancer tissue by immunohistochemistry. Erkan et $a l^{15}$ also reported from cell biology studies that periostin was secreted as an exclusively matrix-specific protein by pancreatic stellate cells, and the protein perpetuated fibrogenic activity and supported tumor cell growth under serum deprivation and hypoxia. 
Intraductal papillary-mucinous neoplasm of the pancreas is also a neoplasm of ductal origin showing a mucinous ectatic pancreatic duct lined with dysplastic papillary epithelium. ${ }^{17,18}$ Intraductal papillary-mucinous neoplasm is considered to be a precursor of invasive pancreatic cancer because one-third of them have an associated component of invasive mucinous or tubular adenocarcinoma. ${ }^{17}$ The adenoma-carcinoma-invasive adenocarcinoma sequence is particularly evident in intraductal papillary-mucinous neoplasm, making this an ideal tumor type for investigating the relationship between periostin expression and tumor development.

The purpose of this study was to characterize the expression pattern of periostin in pancreatic ductal neoplasms, including invasive ductal adenocarcinoma and intraductal papillary-mucinous neoplasms, with a focus on tumor-stromal cell interactions. We comparatively investigated $\alpha$-smooth muscle actin, a marker of myofibroblast, ${ }^{19,20}$ and laminin-5 $\gamma 2$ chain (laminin-332) expression, which is considered to be associated with tumor cell growth and invasion. ${ }^{21}$

\section{Materials and methods}

\section{Cases}

We collected 81 surgically resected ductal adenocarcinoma $(n=35)$, intraductal papillary-mucinous neoplasms $(n=26)$ and mucinous cystic neoplasms $(n=11)$ of the pancreas and chronic pancreatitis $(n=9)$ from the files of the Department of Pathology, the University of Tokyo Hospital. Intraductal papillary-mucinous neoplasms and mucinous cystic neoplasms were selected according to the World Health Organization (WHO) Classification. ${ }^{22,23}$ No ovarian-type stroma (OS) was observed in intraductal papillary-mucinous neoplasms. We classified intraductal papillary-mucinous neoplasms into four categories, namely, adenoma $(n=9)$, non-invasive adenocarcinoma $(n=17)$, adenocarcinoma with minimal invasion (histological invasion; approximately less than $5 \mathrm{~mm}$ in size) $(n=5)$ and adenocarcinoma with invasion recognizable in macroscopic observation (approximately more than $5 \mathrm{~mm}$ in size) $(n=4)$.

\section{Immunohistochemistry}

Immunohistochemical staining was carried out on formalin-fixed, paraffin-embedded tissue sections of surgically resected pancreatic tissues. For antigen retrieval, sections were heated in $1 \mathrm{mM}$ EDTA ( $\mathrm{pH}$ 7.0) for $10 \mathrm{~min}$ by microwave. After overnight incubation with the primary antibody at $4{ }^{\circ} \mathrm{C}$, endogenous peroxidase was blocked with $3 \%$ hydrogen peroxide in TBS for $10 \mathrm{~min}$ at room temperature. Subsequently, the sections were incubated with biotinylated secondary antibody for $30 \mathrm{~min}$ at room temperature, allowed to react for $30 \mathrm{~min}$ with avidin-biotin-peroxidase complex using a Vectastain ABC kit (Vector Laboratories, Burlingame, CA, USA) and counterstained with hematoxylin.

The antibodies used were against periostin (dilution 1:1000; Biovendor, Heidelberg, Germany), $\alpha$-smooth muscle actin (1A4, dilution 1:50; DakoCytomation, Glostrup, Denmark) and laminin-5 $\gamma 2$ chain (D4B5, dilution 1:200, Chemicon, Billerica, MA, USA). Antibodies against MUC1 (Ma695, dilution 1:100; Novocastra Laboratories, Newcastle upon Tyne, UK), MUC2 (Ccp58, dilution 1:200; Novocastra), MUC5AC (CLH2, dilution 1:100; Novocastra) and MUC6 (CLH5, dilution 1:100; Novocastra) were used to determine the mucinbased subclassification of intraductal papillarymucinous neoplasm. ${ }^{24}$

On immunohistochemical study in intraductal papillary-mucinous adenocarcinoma with associated stromal invasion, we evaluated intraductal components and invasive components separately in the same case of them. The immunohistochemical staining results of anti-periostin and $\alpha$-smooth muscle actin were evaluated at the stromal tissue immediately adjacent to neoplastic epithelial cells (within $100 \mu \mathrm{m}$ ) of pancreatic ducts in intraductal papillary-mucinous neoplasm and of infiltrating carcinoma, and were classified by the quantity of positive-staining stromal cells into negative $(<5 \%)$ and positive ( 5 and $>5 \%$ ). Further, we scored the positive staining rate of each immunohistochemistry by percentage, and established the criteria to divide into ' + ' and ' ++ '; $50 \%$ in periostin and in $\alpha$-smooth muscle actin staining. This rate is close to the mean rate of positive ( 5 and $>5 \%$ ) cases. In mucinous cystic neoplasms, we evaluated periostin and $\alpha$-smooth muscle actin staining results using the same criteria as in intraductal papillary-mucinous neoplasm, and then focused on the staining results of 'ovarian-type' stroma. In chronic pancreatitis cases, the staining pattern was observed separately as periductal, inter lobular and intralobular stromal cells. Laminin-5 $\gamma 2$ chain expression was evaluated on proliferating epithelial cells in intraductal papillary-mucinous neoplasms as follows: negative $(<5 \%),+(5-30 \%)$, and $++(>30 \%)$. We established the criteria to divide into ' + ' and ' ++ ' in laminin $5 \gamma 2$ chain immunostaining by the same process as in periostin and $\alpha$-smooth muscle actin stainings. Each slide was reviewed by two authors (NF and YK) through a multiheaded microscope, and a consensus was reached in all cases. All sections were scored twice to confirm the reproducibility of the results.

\section{In Situ Hybridization for Periostin mRNA}

Antisense and sense cRNA probes were prepared by in vitro transcription of ECoRI-XbaI fragment of human periostin cDNA (Takeshita et $a l^{4}$ accession number D13665), using a DIG Labeling MIX (Roche, 
Indianapolis, IN, USA). In situ hybridization for detecting the mRNA of periostin was basically conducted according to the manufacturer's instructions (Roche). Formalin-fixed and paraffinembedded sections $(5 \mu \mathrm{m})$ were deparaffinized, dehydrated and treated in $0.1 \mathrm{M} \mathrm{HCl}$ for $20 \mathrm{~min}$ and in $2 \times$ SSC for $5 \mathrm{~min}$. After immersing in proteinase $\mathrm{K}$ buffer without enzyme, sections were digested with $10 \mathrm{mg} / \mathrm{ml}$ proteinase K (Sigma, St Louis, MO, USA) for $15 \mathrm{~min}$, and treated with $2 \mathrm{mg} / \mathrm{ml}$ glycine in PBS for $2 \mathrm{~min}$. Sections were washed twice in PBS for $1 \mathrm{~min}$ and then postfixed with $4 \%$ paraformaldehyde and washed in PBS for 2 min. After washing again in PBS, they were serially treated with $0.1 \mathrm{M}$ triethanolamine $(\mathrm{pH} 8.0)$ for $5 \mathrm{~min}$ and $0.1 \mathrm{M}$ triethanolamine $/ 0.25 \%$ acetic acid anhydride for $10 \mathrm{~min}$ and then washed in PBS for 5 min. The specimens were prehybridized with hybridization buffer composed of $50 \%$ formamide, $5 \times$ SSC, $5 \times$ Denhardt's solution (Nippon Gene Co Ltd, Tokyo, Japan), and $100 \mu \mathrm{g} / \mathrm{ml}$ yeast tRNA (Sigma) for $1 \mathrm{~h}$ at room temperature. They were then incubated with hybridization buffer containing DIG-labeled antisense or sense probes $(100 \mathrm{ng} / \mathrm{ml})$

Table 1 Clinicopathological and immunohistochemical findings in intraductal papillary-mucinous neoplasms

\begin{tabular}{|c|c|c|c|c|c|c|c|c|c|c|c|}
\hline Case no. & $\begin{array}{c}\text { Age } \\
\text { (years) }\end{array}$ & Sex & $\begin{array}{l}\text { Size } \\
(\mathrm{mm})\end{array}$ & Histology ${ }^{\mathrm{a}}$ & MUC1 & MUC2 & MUC5ac & MUC6 & $\begin{array}{l}\text { Laminin-5 } \gamma 2 \\
\text { chain }\end{array}$ & Periostin & $\begin{array}{c}\alpha-S m o o t h \text { muscle } \\
\text { actin }\end{array}$ \\
\hline \multicolumn{12}{|l|}{ Adenoma } \\
\hline 1 & 68 & $\mathrm{~F}$ & 8 & G & - & - & - & ++ & - & - & ++ \\
\hline 2 & 70 & $\mathrm{~F}$ & 35 & G & - & - & + & ++ & - & - & ++ \\
\hline 3 & 70 & $\mathrm{~F}$ & 70 & G & - & - & ++ & ++ & + & + & ++ \\
\hline 4 & 61 & $\mathrm{M}$ & 12 & G & - & - & - & ++ & - & + & + \\
\hline 5 & 72 & M & 10 & G & + & - & - & + & - & - & + \\
\hline 6 & 68 & $\mathrm{~F}$ & 20 & G & - & - & ++ & + & - & - & ++ \\
\hline 7 & 74 & $\mathrm{M}$ & 20 & G/Int & - & + & ++ & ++ & - & - & ++ \\
\hline 8 & 77 & $\mathrm{M}$ & 10 & G/Int & - & + & ++ & ++ & - & - & + \\
\hline 9 & 65 & $\mathrm{M}$ & 25 & Int & - & ++ & ++ & + & - & - & ++ \\
\hline \multicolumn{12}{|c|}{ Adenocarcinoma (non-invasive) } \\
\hline 10 & 60 & $\mathrm{M}$ & 37 & $\mathrm{G}$ & - & - & ++ & ++ & + & + & + \\
\hline 11 & 65 & $\mathrm{M}$ & 20 & G & - & - & ++ & ++ & + & - & ++ \\
\hline 12 & 72 & $\mathrm{M}$ & 25 & Int & - & ++ & + & + & ++ & + & ++ \\
\hline 13 & 62 & $\mathrm{M}$ & 40 & Int & - & ++ & ++ & + & + & + & ++ \\
\hline 14 & 75 & $\mathrm{M}$ & 50 & Int & - & ++ & + & - & + & ++ & ++ \\
\hline 15 & 69 & $\mathrm{M}$ & 25 & Onc & - & - & ++ & ++ & + & + & ++ \\
\hline 16 & 74 & $\mathrm{M}$ & 15 & Onc & - & - & ++ & ++ & - & - & + \\
\hline 17 & 62 & $\mathrm{~F}$ & 15 & tub & ++ & - & - & - & + & + & + \\
\hline \multicolumn{12}{|c|}{ Intraductal component in adenocarcinoma with microscopical invasion } \\
\hline 18 & 76 & $\mathrm{M}$ & 10 & G & - & - & ++ & + & + & - & ++ \\
\hline 19 & 76 & $\mathrm{M}$ & 25 & G & + & - & ++ & ++ & - & - & ++ \\
\hline 20 & 61 & $\mathrm{M}$ & 20 & Int & + & ++ & ++ & ++ & ++ & + & ++ \\
\hline 21 & 62 & $\mathrm{~F}$ & 35 & Int & - & ++ & + & + & + & ++ & ++ \\
\hline 22 & 71 & $\mathrm{M}$ & 45 & Int & - & + & ++ & ++ & + & + & ++ \\
\hline \multicolumn{12}{|c|}{ Intraductal component in adenocarcinoma with macroscopical invasion } \\
\hline 23 & 76 & $\mathrm{M}$ & 35 & PB & ++ & - & - & + & + & ++ & ++ \\
\hline 24 & 71 & $\mathrm{~F}$ & 25 & G & - & - & + & ++ & + & + & ++ \\
\hline 25 & 67 & $\mathrm{M}$ & 35 & Int & - & + & ++ & + & + & ++ & ++ \\
\hline 26 & 74 & M & 30 & Int & - & ++ & ++ & + & ++ & + & ++ \\
\hline \multicolumn{12}{|c|}{ Invasive component in adenocarcinoma with microscopical invasion } \\
\hline 18 & 76 & $\mathrm{M}$ & & tub & - & - & - & - & ++ & - & ++ \\
\hline 19 & 76 & $\mathrm{M}$ & & tub & + & - & + & + & - & + & ++ \\
\hline 20 & 61 & M & & tub & + & ++ & + & - & ++ & ++ & ++ \\
\hline 21 & 62 & $\mathrm{~F}$ & & tub & - & ++ & - & - & + & ++ & + \\
\hline 22 & 71 & $\mathrm{M}$ & & tub & - & + & + & ++ & + & ++ & ++ \\
\hline \multicolumn{12}{|c|}{ Invasive component in adenocarcinoma with macroscopical invasion } \\
\hline 23 & 76 & $\mathrm{M}$ & & tub & ++ & - & + & + & ++ & ++ & ++ \\
\hline 24 & 71 & $\mathrm{~F}$ & & por & ++ & - & + & + & ++ & ++ & + \\
\hline 25 & 67 & M & & tub & ++ & - & + & + & ++ & ++ & ++ \\
\hline 26 & 74 & $\mathrm{M}$ & & tub/muc & - & ++ & - & + & ++ & + & + \\
\hline
\end{tabular}

F, female; M, male; G, gastric type; Int, intestinal type; Onc, oncocytic type; PB, pancreatobiliary type; muc, mucinous carcinoma invasion; por, poorly differentiated adenocarcinoma invasion; tub, well or moderately differentiated tubular adenocarcinoma invasion.

${ }^{a}$ Histology and mucin-based subtypes in intraductal papillary mucinous neoplasms, and invasive feature of adenocarcinoma cases with associated stromal invasion. 

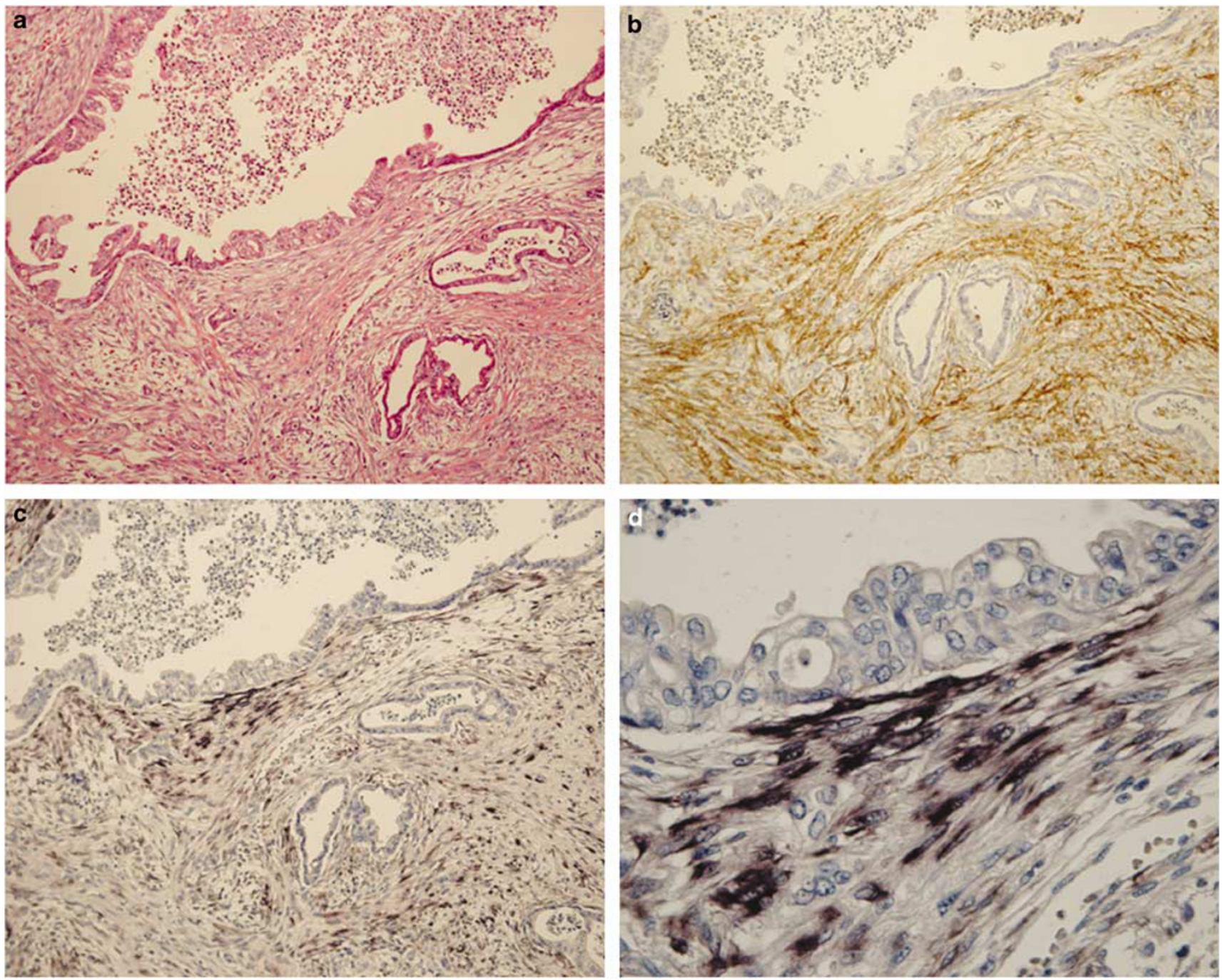

Figure 1 Periostin expression in pancreatic ductal adenocarcinoma. (a) Pancreatic invasive ductal adenocarcinoma with prominent desmoplastic reaction (HE stain). (b) Periostin immunohistochemistry shows positive staining of desmoplastic stromal cells around infiltrating cancer glands. (c) In situ hybridization of periostin on serial sections of panels a and b shows that mRNA signals are observed in spindle cells of desmoplastic stroma. (d) A high power view of (c).

overnight at $58^{\circ} \mathrm{C}$. After hybridization, sections were rinsed twice in $5 \times \mathrm{SSC}$ for $15 \mathrm{~min}$ at $58^{\circ} \mathrm{C}$, and incubated twice in RNase buffer composed of $10 \mathrm{mM}$ Tris-HCL, $500 \mathrm{mM} \mathrm{NaCl}$ and $1 \mathrm{mM}$ EDTA at $37^{\circ} \mathrm{C}$ for $15 \mathrm{~min}$. To remove unhybridized RNA, the sections were incubated with $40 \mu \mathrm{g} / \mathrm{ml}$ RNase A in RNase buffer at $37^{\circ} \mathrm{C}$ for $30 \mathrm{~min}$, followed by one washing in RNase buffer at $37^{\circ} \mathrm{C}$ for $15 \mathrm{~min}$, twice in $0.2 \times \mathrm{SSC}$ at $58^{\circ} \mathrm{C}$ for $20 \mathrm{~min}$ and once in $0.2 \times \mathrm{SSC}$ for $20 \mathrm{~min}$ at room temperature. In situ hybridization signals were detected immunohistochemically with alkaline phosphatase-conjugated anti-DIG antibody (1:500; Roche) after blocking with 10\% sheep serum in TBS for $20 \mathrm{~min}$. Signals were revealed with alkaline phosphatase substrate solution containing levamisole (dark blue). Sections were counterstained with Mayer's hematoxylin and mounted with aqueous mounting medium.

\section{Statistics}

Statistical analysis was performed using Excel $^{\circledR}$ 2003 for Windows (Microsoft, Redmond, WA, USA). Fisher's exact probability test was used to assess the correlation between periostin protein expression and clinicopathological findings. Statistical significance was defined as $P<0.05$.

\section{Results}

\section{Clinicopathological Characteristics}

Patients with pancreatic ductal adenocarcinoma included 21 men and 14 women, with a mean age of 66 years (range, 40-79 years). The mean tumor diameter of ductal adenocarcinomas was $31 \mathrm{~mm}$ (range, $10-40 \mathrm{~mm}$ ). Twenty-six ductal adenocarcinomas were 

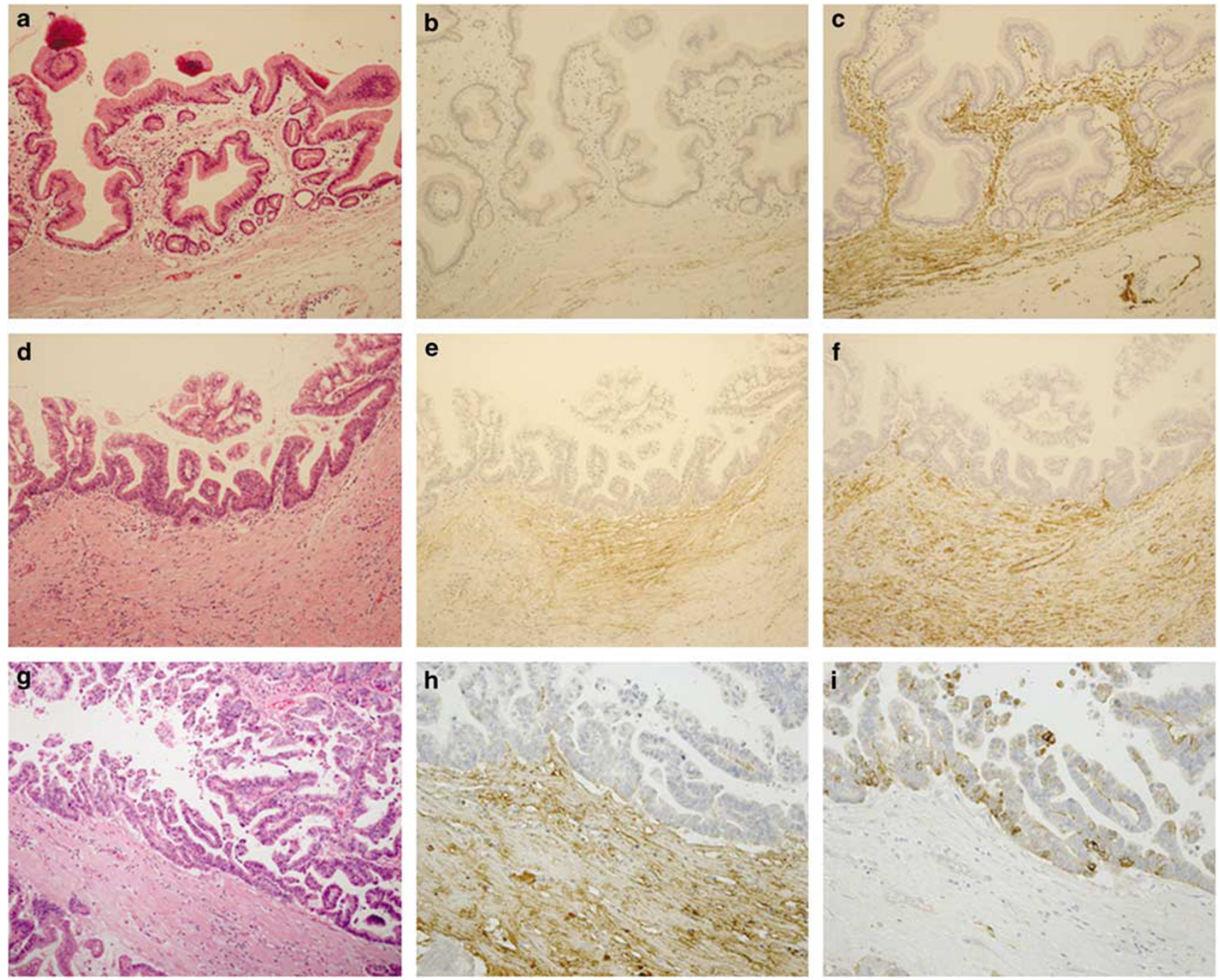

Figure 2 Periostin and $\alpha$-smooth muscle actin expression in intraductal papillary mucinous neoplasms of the pancreas. (a-c) Part of the ectatic ductal wall of intraductal papillary-mucinous adenoma (case 6). (a) HE stain, (b) periostin (c) $\alpha$-smooth muscle actin. (d-f) Part of the ectatic ductal wall of intraductal papillary-mucinous adenocarcinoma without invasion (case 12). (d) HE stain, (e) Periostin and (f) $\alpha$-smooth muscle actin. (g-i) Intraductal component of intraductal papillary-mucinous adenocarcinoma with microscopic stromal invasion (Case 21). (g) HE stain (h) periostin and (i) Laminin-5 $\gamma 2$ chain. Close localization of periostin and laminin-5 $\gamma 2$ chain-positive cells is seen in panels $\mathbf{h}$ and $\mathbf{i}$.

located in the head and the other nine were in the body and/or tail of the pancreas. Patients with intraductal papillary-mucinous neoplasm included 19 men and 7 women, with a mean age of 69 years (range, 61-77 years) (Table 1). The mean tumor long axes of intraductal papillary-mucinous neoplasms were $23 \mathrm{~mm}$ (range, $8-70 \mathrm{~mm}$ ) in adenoma and $29 \mathrm{~mm}$ (range, $10-45 \mathrm{~mm}$ ) in adenocarcinoma. All 11 patients with mucinous cystic neoplasm were women, with a mean age of 45 years (range, 33-69 years). The mean tumor diameter of mucinous cystic neoplasms was $91 \mathrm{~mm}$ (range, $25-170 \mathrm{~mm}$ ). The thickness of the cystic wall of mucinous cystic neoplasms was up to $7 \mathrm{~mm}$ (mean, $4 \mathrm{~mm}$ ). All patients with chronic pancreatitis were men, with a mean age of 49 years (range, 6-66 years).

\section{Immunohistochemistry of Periostin and $\alpha$-Smooth Muscle Actin}

In the non-neoplastic pancreas, there was no positive periostin in epithelial cells of the pancreas, including ductal, acinar, and endocrine cells of the pancreas. Stromal cells around normal pancreatic ducts expressed no periostin. Immunoreactive periostin was observed in the stroma around cancer cells in all invasive ductal adenocarcinoma ( + or,$++ n=35$ ). Periostin deposition was most prominent in the lesion immediately adjacent to infiltrating cancer cells and was usually weak to absent in the stroma distant to cancer cells (Figure 1a and b). Small numbers of weak periostin-positive foci $(<5 \%)$ were scattered on the cancer epithelium on immunohistochemistry. 

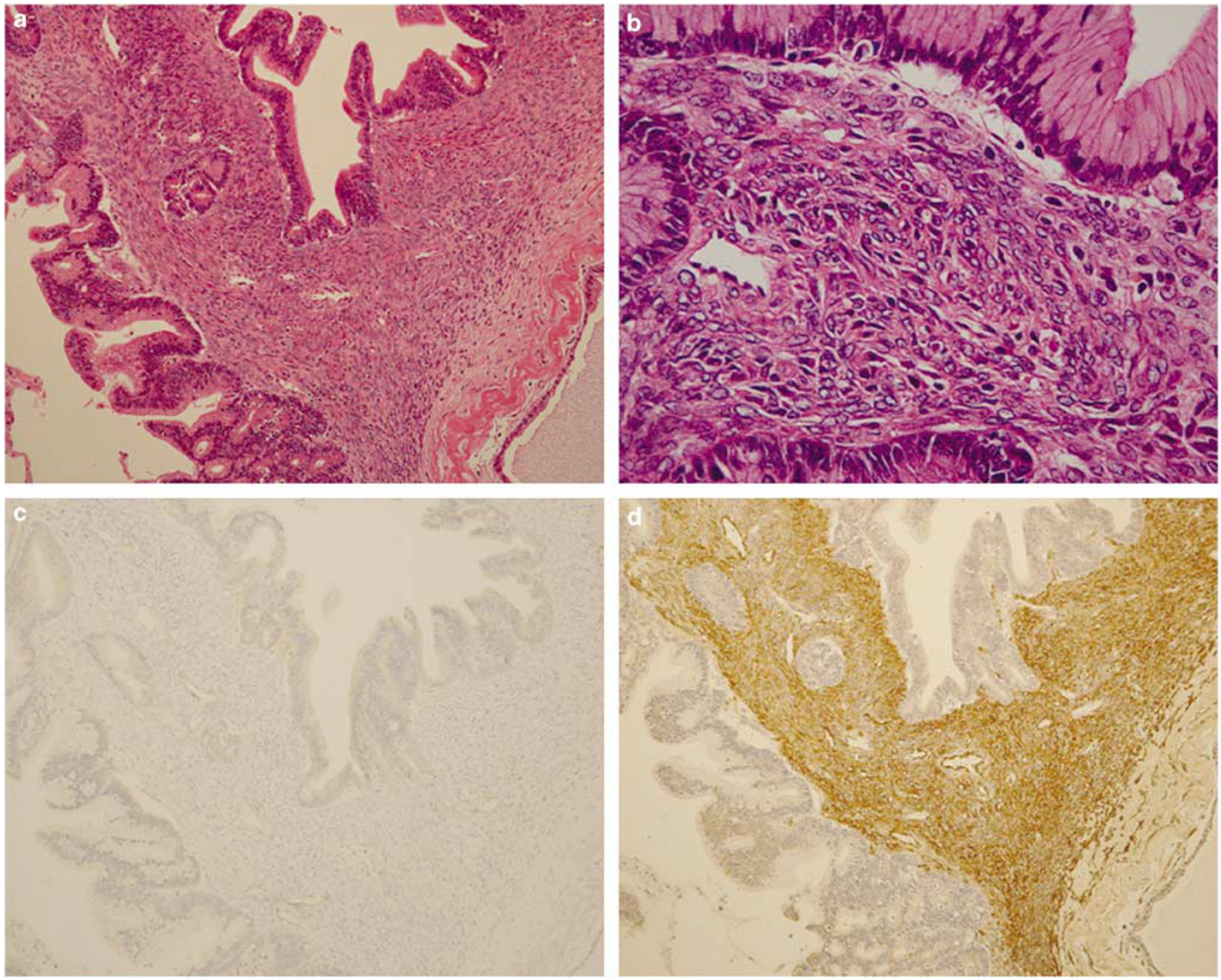

Figure 3 Periostin deposition in pancreatic mucinous cystic neoplasm. (a and b) Cellular stroma, called 'ovarian-type' stroma, are seen beneath the proliferating epithelium (HE stain). (c) Periostin immunohistochemistry shows negative staining for 'ovarian-type' stromal cells. (d) $\alpha$-Smooth muscle actin immunohistochemistry on serial sections of panels (a-c) is strongly positive for stromal cells.

The peri-cancerous stroma of invasive components of intraductal papillary-mucinous adenocarcinoma also often showed immunoreactivity of periostin $(-, 0 ;+, 2 ;++, 6$ cases). Fifteen intraductal papillary-mucinous neoplasms (58\%) showed stromal periostin expression $(+$ or ++$)$; 2 of 9 adenomas and 13 of 17 adenocarcinomas (Figure 2). In all intraductal papillary-mucinous neoplasms, there were bunches of $\alpha$-smooth muscle actin-positive cells in the fibrous stromal tissue, both surrounding stroma of intraductal components $(-, 0 ;+, 6 ;++, 20$ cases $)$ and invasive cancer components $(-, 0 ;+, 3 ;++, 6$ cases $)$.

In 2 of 11 mucinous cystic neoplasms, stromal tissue immediately adjacent to the epithelial tumor on the inner surface showed foci of periostin immunoreactivity; however, no staining of the 'ovarian-type' stroma (Figure 3). Stroma with periostin deposition was accompanied with chronic inflammation and fibrosis. On the other hand, $\alpha$-smooth muscle actin-positive cells were abundant in fibrous areas, including 'ovarian-type' stroma of all mucinous cystic neoplasms (Figure 3).

In chronic pancreatitis, immunoreactive periostin was observed mainly in the peri-lobular and interacinar areas showing a meshwork-like or fibrillary pattern, which was accompanied by many $\alpha$-smooth muscle actin-positive cells (Figure 4). No or only weak staining was seen in interlobular collagenous fibrous tissue in chronic pancreatitis.

\section{In Situ Hybridization of Periostin in Ductal Adenocarcinoma of the Pancreas}

To clarify the localization of the periostin gene expression in pancreatic ductal adenocarcinoma, we performed in situ mRNA hybridization of five 

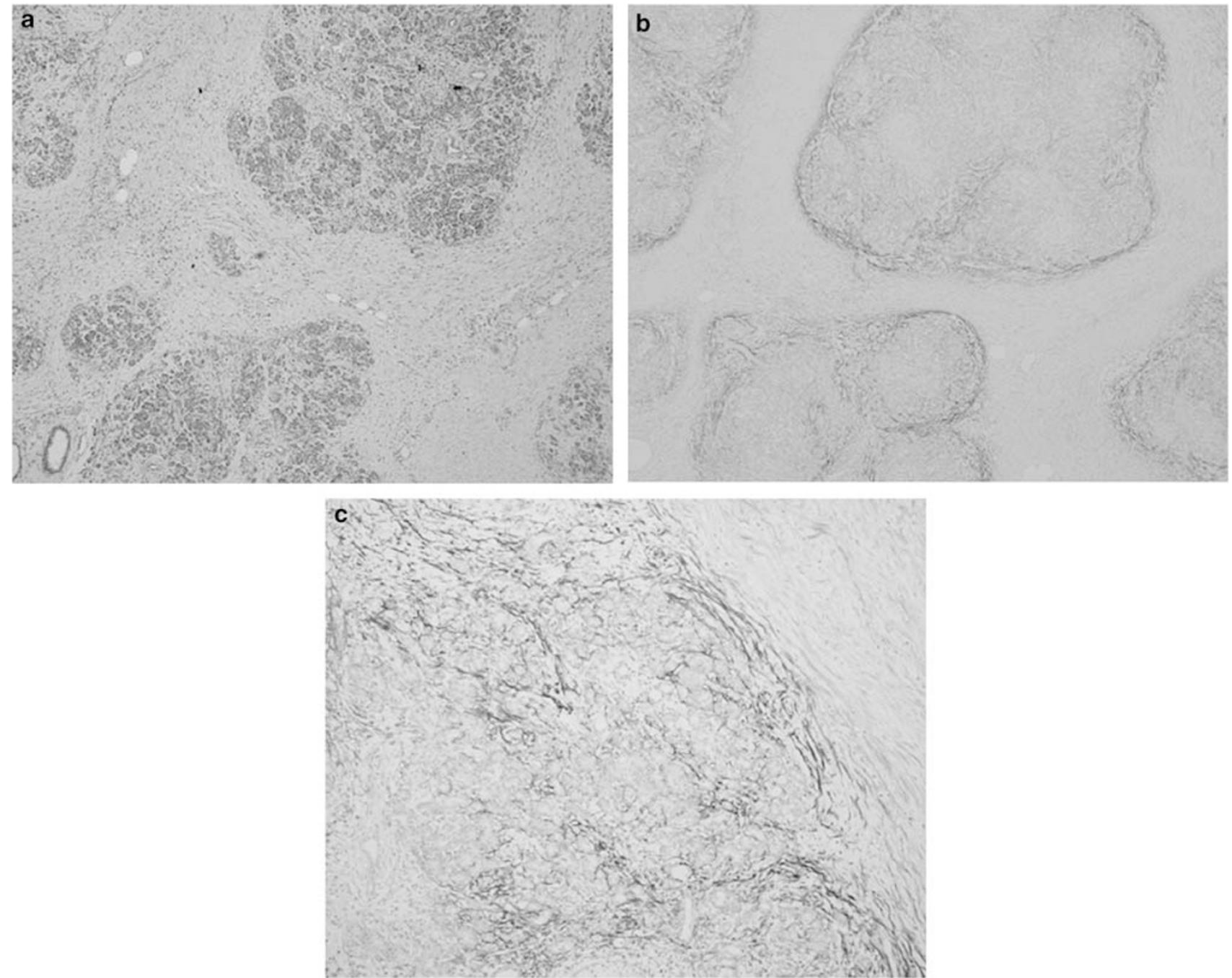

Figure 4 Periostin deposition in chronic pancreatitis. (a) Lobular atrophy with interlobular and intralobular fibrosis and mild inflammatory cell infiltration is observed. (b) Periostin immunohistochemistry shows perilobular and intralobular positive staining. Owing to intralobular (interacinar) myofibroblastic proliferation, a perilobular meshwork-like staining pattern is seen. (c) Meshwork-like staining pattern is characteristic in this field.

tissue samples. Periostin mRNA signals were only detected in stromal spindle cells corresponding to myofibroblasts of the pancreas, but not in carcinoma cells (Figure 1c and d).

\section{Periostin Expression in Intraductal Papillary- Mucinous Neoplasms and its Clinicopathological Characteristics}

To further clarify the significance of periostin expression in intraductal papillary-mucinous neoplasms, the correlation of periostin immunodeposition was evaluated with clinicopathological characteristics, and immunohistochemistry of mucin and laminin$5 \gamma 2$ chain (Tables 1 and 2).

Patient age or gender showed no significant correlation with periostin deposition, but the factors of tumor pathology showed positive correlations
(Table 2). Intraductal papillary-mucinous adenocarcinoma showed a significantly higher frequency of periostin deposition than adenoma $(P=0.014)$. In intraductal papillary-mucinous adenocarcinoma with stromal invasion, we separately evaluated the peri-ectatic ducts of intraductal neoplasm and their associated invasive cancer tissue. The positive rate of immunoreactive periostin in non-invasive areas tended to increase according to the histological grade of neoplasic epithelium as follows: 2 of 9 $(22 \%)$ in adenoma, 6 of $8(75 \%)$ in non-invasive adenocarcinoma, 3 of $5(60 \%)$ in adenocarcinoma with microscopical invasion and 4 of $4(100 \%)$ in adenocarcinoma with macroscopical invasion.

According to the MUC immunophenotypes and histology of proliferating epithelial cells, ${ }^{24}$ intraductal papillary-mucinous neoplasms were subclassified into gastric $(n=11)$, intestinal $(n=8)$, oncocytic $(n=2)$, pancreatobiliary $(n=1)$, tubular 
Table 2 Relationship between periostin protein deposition and clinicopathological characteristics in intraductal papillarymucinous neoplasms

\begin{tabular}{|c|c|c|c|c|}
\hline & & Peric & ression & \\
\hline & $\mathrm{n}$ & - & $+/++$ & $\mathrm{P}$-value \\
\hline Age (years) & & & & \\
\hline$<70$ & 12 & 4 & 8 & NS \\
\hline$\geq 70$ & 14 & 7 & 7 & \\
\hline Gender & & & & \\
\hline Male & 19 & 8 & 11 & NS \\
\hline Female & 7 & 3 & 4 & \\
\hline Tumor size $(\mathrm{cm})$ & & & & \\
\hline$<2.5$ & 11 & 8 & 3 & 0.015 \\
\hline$\geq 2.5$ & 15 & 3 & 12 & \\
\hline Histological grade & & & & \\
\hline Adenoma & 9 & 7 & 2 & 0.014 \\
\hline Adenocarcinoma & 17 & 4 & 13 & \\
\hline Infiltration & & & & \\
\hline Non & 17 & 12 & 5 & 0.038 \\
\hline Exist & 9 & 2 & 7 & \\
\hline Histological phenotyp & & & & \\
\hline Intestinal type & 9 & 1 & 8 & 0.036 \\
\hline Non-intestinal type & 17 & 10 & 7 & \\
\hline Laminin-5 $\gamma 2$ & & & & \\
\hline$(-)$ & 10 & 9 & 1 & $<0.001$ \\
\hline$(+) /(++)$ & 16 & 2 & 14 & \\
\hline
\end{tabular}

NS, no significance.

$(n=1)$ and mixed subtypes (gastric and focal intestinal) $(n=2)$. Surrounding stroma of the intestinal subtype showed a higher frequency of periostin deposition than in the non-intestinal subtypes $(P=0.036)$ (Table 2).

Laminin-5 $\gamma 2$ chain expression was observed in neoplastic epithelial cells. Several cases showed linear basement membrane staining partly in intraductal papillary-mucinous neoplasms. Invasive carcinoma components of intraductal papillarymucinous neoplasm showed laminin-5 $\gamma 2$ chainpositive staining except for one case. Foci of positive cells were more frequently observed in intraductal components of intraductal papillary-mucinous adenocarcinoma $(88 \%)$ than in those of adenoma $(11 \%)(P=0.002)$. Twenty-one $(80.8 \%)$ of 26 intraductal papillary-mucinous neoplasms showed the same staining results of laminin-5 $\gamma 2$ chain as of periostin, negative $(-)$ or positive $(+$ or ++$)$. The positive rate of periostin deposition was strongly correlated with that of laminin-5 $\gamma 2$ chain in intraductal papillary-mucinous neoplasms $(P<0.001)$ (Table 2). On histological review, close location or contact between laminin-5 $\gamma 2$ chain-positive neoplastic epithelial cells and periostin-positive stroma was observed in at least three cases (Figure $2 \mathrm{~h}$ and $\mathrm{i}$ ). In other cases, laminin-5 $\gamma 2$ chain-positive cells tended to be scattered around the apical portion of the proliferating epithelium in intraductal papillarymucinous neoplasms.

\section{Discussion}

In this study, periostin deposition was observed in the desmoplastic stroma with mesenchymal cells, suggestive of myofibroblasts, around neoplastic cells not only in invasive ductal adenocarcinoma but also in intraductal papillary-mucinous neoplasms, the non-invasive stage of pancreatic neoplasm. In intraductal papillary-mucinous neoplasm, a higher frequency of periostin deposition was correlated with higher histological grade, higher frequency of laminin-5 $\gamma 2$ chain expression and 'intestinal phenotype' of the proliferating epithelium.

We studied periostin expression because of the differential expression of its gene on microarray profiles of pancreatic ductal adenocarcinomas in previous studies. ${ }^{12,13}$ On our immunohistochemistry, all samples of ductal adenocarcinoma showed strong stromal staining of periostin, whereas cancer and inflammatory cells were always non-stained. These findings are in accordance with previous reports. ${ }^{15,16}$ We also detected positive signals of periostin mRNA only in spindle cells, probably corresponding to myofibroblasts, in stroma surrounding cancer cells by in situ hybridization.

Stromal cells of the pancreas represent a heterogeneous population of spindle cells, including capillary endothelial cells, fibroblasts and activated fibroblasts known as myofibroblasts. Recently, pancreatic stellate cells have been identified in the normal pancreas, chronic pancreatitis and PDAC. ${ }^{25,26}$ Pancreatic stellate cells can transdifferentiate from inanctive retinoid/lipid storing status to an activated myofibroblastic status. ${ }^{19,20}$ The expression of $\alpha$-smooth muscle actin is considered one of the earliest events in stellate cell activation, occurring before the deposition of collagen. ${ }^{19,27}$ In this study, because immunoreactive periostin was always observed with $\alpha$-smooth muscle actinpositive spindle cells, these cells are regarded as myofibroblasts.

We observed focal periostin expression in the stroma of several cases of intraductal papillarymucinous neoplasms, even if the tumor was in the non-invasive stage. Through the progression of intraductal papillary-mucinous neoplasm to invasive carcinoma, the ductular basement membrane is eroded by cancer cells and tumor cells invade the surrounding pancreatic parenchyma. Variable stromal responses have also been described in the pre-invasive stage of neoplastic lesions in other organs. ${ }^{28,29}$ Several growth factors are speculated to act in a paracrine manner to induce a stromal reaction. ${ }^{20,29}$

Laminins are a family of basement membrane proteins that are associated with cell differentiation, adhesion and migration, as well as structural 
components. ${ }^{21}$ The laminin-5 $\gamma 2$ chain is expressed in cells of various carcinomas, including pancreatic ductal adenocarcinoma. According to the previous observation, laminin-5 $\gamma 2$ chain expression is found stronger in frontline invasive cancer cells at the epithelial-stromal interface. ${ }^{21}$ In this study, laminin-5 $\gamma 2$ chain tended to increase the amount of positive cells as intraductal papillary-mucinous neoplasm developed, as reported previously. ${ }^{30}$ These findings suggest that laminin-5 $\gamma 2$ chainpositive cells in the intraductal components of them might show potential invasiveness or be connected to invasive carcinoma. ${ }^{30}$ The frequency of periostin expression in adenoma and adenocarcinoma correlated with that of laminin-5 $\gamma 2$ chain, and $80.8 \%$ of intraductal papillary-mucinous neoplasms showed the same immunostaining results, negative or positive, between stromal periostin expression and epithelial laminin-5 $\gamma 2$ chain expression in the study $(P<0.001)$. Close localization or contact between laminin-5 $\gamma 2$ chain and periostin-positive stroma was observed in at least three cases. Taken together, the increased frequency of laminin-5 $\gamma 2$ chain immunoreactive tumor cells suggests an indicator of the increased potential of invasiveness in intraductal papillary-mucinous neoplasm. A neoplasm with frequent laminin-5 $\gamma 2$ chain-positive cells may affect stromal cells. Although direct interaction between periostin and laminin-5 $\gamma 2$ chain has not been observed, laminin-5 $\gamma 2$ chain strongly promotes cellular scattering, migration and adhesion through interaction with integrins $\alpha 3 \beta 1, \alpha 6 \beta 1$ and $\alpha 6 \beta 4$ in vitro, ${ }^{21}$ whereas $\beta 4$ integrin complex acts as a cell surface receptor of periostin in pancreatic cancer cells. ${ }^{16}$

Stromal periostin staining was frequently observed not only in ductal adenocarcinomas and intraductal papillary-mucinous neoplasms but also in chronic inflammatory processes, such as chronic pancreatitis and small foci of obstructive pancreatitis with lobular atrophy and perilobular fibrosis. Peri-lobular and mesh-like immunostaining patterns of periostin were characteristic, and no or little positivity was seen in interlobular thick fibrous bands in chronic pancreatitis. The distribution of periostin immunoreactivity is considered to correspond with that of stellate cells in the normal pancreas. ${ }^{20}$

'Ovarian-type' stroma is known as a characteristic histologic feature of pancreatic mucinous cystic neoplasm, forming a band of densely packed spindle cells beneath the epithelium, and are now widely used as a criterion for diagnosis. ${ }^{23,31}$ These stromal cells frequently shows estrogen receptor, progesterone receptor, $\alpha$-inhibin and $\alpha$-smooth muscle actin. ${ }^{31}$ In this study, we found no periostin expression in distinct 'ovarian-type' stroma in mucinous cystic neoplasms of the pancreas, suggesting that characteristic cellular stromal tissue in them has a different nature from myofibroblastic proliferation in ductal neoplasms and chronic pancreatitis.
In conclusion, we have shown that periostin is expressed and deposited in the stroma of human pancreatic ductal neoplasms, including intraductal papillary-mucinous neoplasms and ductal adenocarcinomas, and chronic pancreatitis. Immunohistochemical deposition of periostin increased according to the histological grade of neoplastic epithelium in intraductal papillary-mucinous neoplasms. This is the first report to describe the periostin immunohistochemistry in intraductal papillary mucinous neoplasm of the pancreas. It is speculated that tumor-stromal cell interaction appears even in non-invasive stages of ductal neoplasms of the pancreas. The precise mechanism inducing the expression of periostin in stroma will be the subject of future studies.

\section{Acknowledgements}

This work was supported by a Grant-in-Aid for Scientific Research (C) (18590322). We thank Dr Takeshi Kashima for useful discussion.

\section{Disclosure/conflict of interest}

There is no ethical problem or conflict of interest with regard to this manuscript.

\section{References}

1 Mahadevan D, Von Hoff DD. Tumor-stroma interactions in pancreatic ductal adenocarcinoma. Mol Cancer Ther 2007;6:1186-1197.

2 Chu GC, Kimmelman AC, Hezel AF, et al. Stromal biology of pancreatic cancer. J Cell Biochem 2007;101: 887-907.

3 Sato N, Maehara N, Goggins M. Gene expression profiling of tumor-stromal interactions between pancreatic cancer cells and stromal fibroblasts. Cancer Res 2004;64:6950-6956.

4 Takeshita S, Kikuno R, Tezuka K, et al. Osteoblastspecific factor 2: cloning of a putative bone adhesion protein with homology with the insect protein fasciclin I. Biochem J 1993;294:271-278.

5 Horiuchi K, Amizuka N, Takeshita S, et al. Identification and characterization of a novel protein, periostin, with restricted expression to periosteum and periodontal ligament and increased expression by transforming growth factor beta. J Bone Miner Res 1999;14: 1239-1249.

6 Kudo Y, Ogawa I, Kitajima S, et al. Periostin promotes invasion and anchorage-independent growth in the metastatic process of head and neck cancer. Cancer Res 2006;66:6928-6935.

7 Sasaki H, Lo KM, Chen LB, et al. Expression of periostin, homologous with an insect cell adhesion molecule, as a prognostic marker in non-small cell lung cancers. Jpn J Cancer Res 2001;92:869-873.

8 Gillan L, Matei D, Fishman DA, et al. Periostin secreted by epithelial ovarian carcinoma is a ligand for alpha(V) beta(3) and alpha(V)beta(5) integrins and promotes cell motility. Cancer Res 2002;62:5358-5364. 
9 Grigoriadis A, Mackay A, Reis-Filho JS, et al. Establishment of the epithelial-specific transcriptome of normal and malignant human breast cells based on MPSS and array expression data. Breast Cancer Res 2006;8:R56.

10 Shao R, Bao S, Bai X, et al. Acquired expression of periostin by human breast cancers promotes tumor angiogenesis through up-regulation of vascular endothelial growth factor receptor 2 expression. Mol Cell Biol 2004;24:3992-4003.

11 Bao S, Ouyang G, Bai X, et al. Periostin potently promotes metastatic growth of colon cancer by augmenting cell survival via the Akt/PKB pathway. Cancer Cell 2004;5:329-339.

12 Friess H, Ding J, Kleeff J, et al. Microarray-based identification of differentially expressed growth- and metastasis-associated genes in pancreatic cancer. Cell Mol Life Sci 2003;60:1180-1199.

13 Crnogorac-Jurcevic T, Missiaglia E, Blaveri E, et al. Molecular alterations in pancreatic carcinoma: expression profiling shows that dysregulated expression of S100 genes is highly prevalent. J Pathol 2003;201: 63-74.

14 Buchholz M, Kestler HA, Holzmann K, et al. Transcriptome analysis of human hepatic and pancreatic stellate cells: organ-specific variations of a common transcriptional phenotype. J Mol Med 2005;83: 795-805.

15 Erkan M, Kleeff J, Gorbachevski A, et al. Periostin creates a tumor-supportive microenvironment in the pancreas by sustaining fibrogenic stellate cell activity. Gastroenterology 2007;132:1447-1464.

16 Baril P, Gangeswaran R, Mahon PC, et al. Periostin promotes invasiveness and resistance of pancreatic cancer cells to hypoxia-induced cell death: role of the beta4 integrin and the PI3k pathway. Oncogene 2007;26:2082-2094.

17 Hruban RH, Fukushima N. Pancreatic adenocarcinoma: update on the surgical pathology of carcinomas of ductal origin and PanINs. Mod Pathol 2007;20(Suppl 1): S61-S70.

18 Sohn TA, Yeo CJ, Cameron JL, et al. Intraductal papillary mucinous neoplasms of the pancreas: an updated experience. Ann Surg 2004;239:788-797; discussion 79

19 Apte MV, Park S, Phillips PA, et al. Desmoplastic reaction in pancreatic cancer: role of pancreatic stellate cells. Pancreas 2004;29:179-187.
20 Omary MB, Lugea A, Lowe AW, et al. The pancreatic stellate cell: a star on the rise in pancreatic diseases. J Clin Invest 2007;117:50-59.

21 Miyazaki K. Laminin-5 (laminin-332): unique biological activity and role in tumor growth and invasion. Cancer Sci 2006;97:91-98.

22 Longnecker DS, Adler G, Hruban RH. Intraductal papillary-mucinous neoplasms of the pancreas. In: Hamilton SR, Aaltonen LA (eds). World Health Organization Classification of Tumours. Pathology and Genetics of Tumours of the Digestive System. IARC Press: Lyon, 2000, pp 237-240.

23 Zamboni G, Kloppel G, Hruban RH. Mucinous cystic neoplasms of the pancreas. In: Hamilton SR, Aaltonen LA (eds). World Health Organization Classification of Tumours. Pathology and Genetics of Tumours of the Digestive System. IARC Press: Lyon, 2000, pp 234-236.

24 Furukawa T, Kloppel G, Volkan Adsay N, et al. Classification of types of intraductal papillarymucinous neoplasm of the pancreas: a consensus study. Virchows Arch 2005;447:794-799.

25 Apte MV, Haber PS, Applegate TL, et al. Periacinar stellate shaped cells in rat pancreas: identification, isolation, and culture. Gut 1998;43:128-133.

26 Bachem MG, Schneider E, Gross H, et al. Identification, culture, and characterization of pancreatic stellate cells in rats and humans. Gastroenterology 1998;115:421-432.

27 Ooi LP, Crawford DH, Gotley DC, et al. Evidence that 'myofibroblast-like' cells are the cellular source of capsular collagen in hepatocellular carcinoma. J Hepatol 1997;26:798-807.

28 Ronnov-Jessen L, Petersen OW, Bissell MJ. Cellular changes involved in conversion of normal to malignant breast: importance of the stromal reaction. Physiol Rev 1996;76:69-125.

29 Mueller MM, Fusenig NE. Friends or foes-bipolar effects of the tumour stroma in cancer. Nat Rev Cancer 2004;4:839-849.

30 Fukushima N, Sakamoto M, Hirohashi S. Expression of laminin-5-gamma-2 chain in intraductal papillarymucinous and invasive ductal tumors of the pancreas Mod Pathol 2001;14:404-409.

31 Fukushima N, Fukayama M. Mucinous cystic neoplasms of the pancreas: pathology and molecular genetics. J Hepatobiliary Pancreat Surg 2007;14:238-242. 